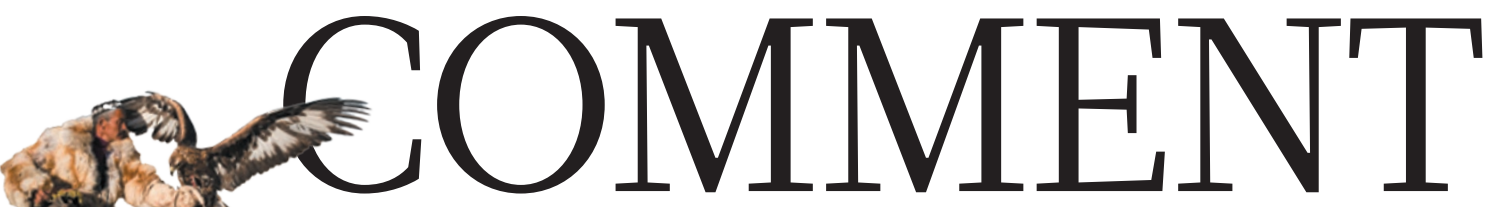

ORWTHOLoty On the enduring relationship between birds and people $\mathbf{p} . \mathbf{2 5}$
ENVIRONMENT Psychological dissociation plagues our relationship with nature $\mathbf{p . 2 6}$
GENOMICS High-tech

Smithsonian exhibition

celebrates double helix p.28
OBITUARY Kenneth Wilson, physics revolutionary, remembered $\mathbf{p . 3 0}$

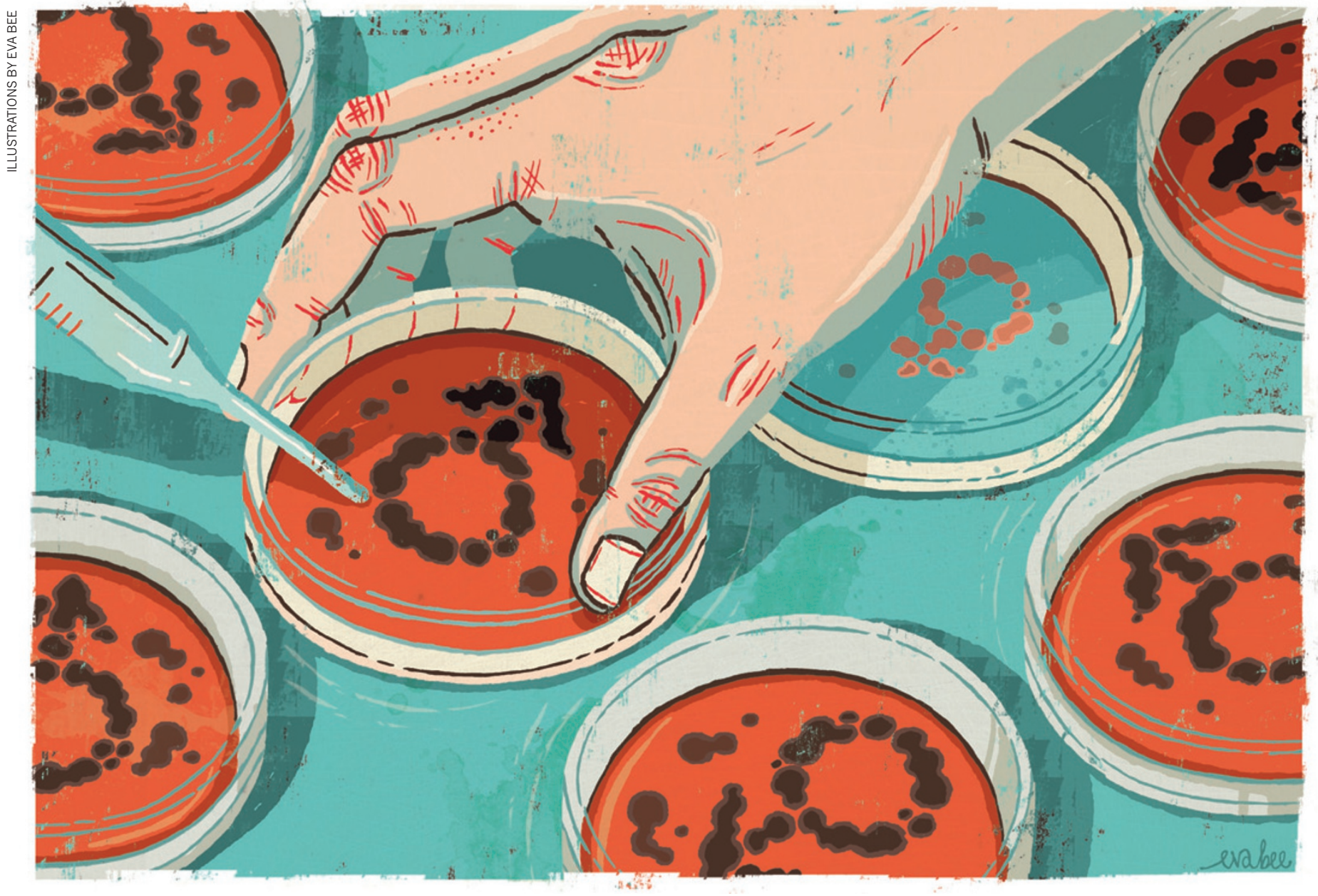

\title{
Cell sex matters
}

\section{Male and female cells can behave differently - it is time that researchers, journals and funders took this seriously, says Elizabeth Pollitzer.}

$\mathrm{T}$ Transplanting muscle-derived stem cells into diseased muscle regenerates it - a phenomenon that holds major potential for human therapies. But for years, researchers were puzzled by the unpredictability of these cells - sometimes they would promote fast regeneration, at other times none at all. Then, in 2007, a group led by Johnny Huard, a stem-cell researcher at the University of Pittsburgh in Pennsylvania, hit on the rather surprising explanation - sex ${ }^{1}$. Muscle stem cells taken from female mice regenerate new muscle much faster than those from male mice when transplanted into diseased muscle of mice of either sex.

Researchers have also found that cells taken from male and female mice respond differently to stress ${ }^{2}$, and that human cells exhibit wildly different concentrations of many metabolites across the sexes ${ }^{3}$. Evidence is mounting that cells differ according to sex, irrespective of their history of exposure to sex hormones. These differences could have major implications for the susceptibility to and course of many diseases, their diagnosis and treatment. However, most cell biologists do not note whether the cells they are using come from males or females ${ }^{4}$.

Between 1997 and 2001, ten prescription drugs were withdrawn from the 
$\checkmark$ market by the US Food and Drug Administration (FDA), eight of which were more dangerous to women than to men (see go.nature.com/ksindo). The ingredients used in non-prescription drugs can also pose greater health risks to women. In 2000, for instance, the FDA took steps to remove phenylpropanolamine, a component of many over-the-counter medications, from all drug products because of a reported increased risk of bleeding into the brain or into tissue around the brain in women but not in men. Such drug therapies are developed through basic research - but what if sex-related differences in studied cells contribute in a significant way to the observed effects?

This major potential problem has a relatively easy solution. Researchers, journals and peer reviewers must simply pay attention to cell sex, and whether it could affect findings.

\section{YOU'VE GOT MALE}

As a computing expert, the sex of cells has never had a direct influence on my research. I learned about the problem as director of genSET, a project funded by the European Union that looked at how gender issues are, or should be, addressed in science (see www.genderinscience.org). The biggest concern turned out to be not inequities in hiring or funding, but the absence of gender considerations in the design, analysis and reporting of bench experiments.

In 2010, genSET convened a panel of 14 experts who reviewed more than 120 papers from a range of fields - not just cell biology - and produced a consensus report with 13 recommendations (see go.nature. com/kxnpfn). They call for more thorough and systematic inclusion of sex and gender

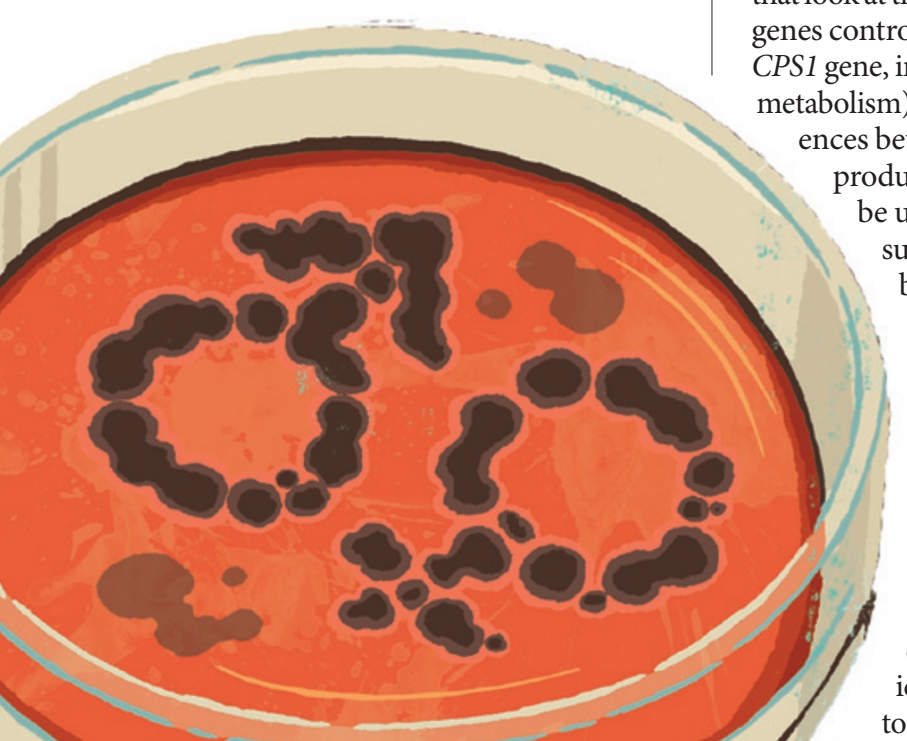

analysis in study design, in the research process and in the training of scientists and lab managers.

The fact that sex and gender do matter has been recognized for years in clinical research, a field in which researchers have often disproportionately sampled men. For instance, a 2009 review $^{5}$ of hundreds of clinical studies in cancer revealed that $75 \%$ of them under-represented women, suggesting that women have less access to experimental medicine than men, and might respond less effectively to approved drugs.

The imbalances extend to basic research. When the journal Pain reviewed its publication record in 2007 ,

it found that at least

$79 \%$ of animal studies published in the journal over the preceding ten years used male subjects only, with just $8 \%$ of studies on

\section{"If working with only one sex or gender, then specify that, and explain why."}

females only. Another 4\% were designed explicitly to test for sex differences and the rest did not specify ${ }^{6}$.

Hormones do not provide the entire explanation for these sex differences - embryonic neurons isolated from male and female rats before being exposed to sex hormones have different cellular responses to stress. Female cells are more sensitive to agents that induce programmed cell death (apoptosis), whereas male cells react more to oxygen deprivation, ischaemia and other forms of stress ${ }^{7}$. Female cells also show greater sensitivity to ethanol than do male cells - again, independent of hormonal effects ${ }^{2}$.

These dimorphisms in cellular behaviour may be because of different metabolic pathways. Sex-stratified analyses of genomic data that look at the location and expression of the genes controlling key enzymes (such as the CPS1 gene, involved in protein and nitrogen metabolism) have revealed significant differnces between females and males ${ }^{3}$. The products of metabolic reactions may be used as biomarkers for diseases such as diabetes and Alzheimer's, but clinicians might not always realize that they should expect different metabolite levels in men and women.

\section{WAY FORWARD}

My appreciation of the importance of this issue is helped by the fact that in my first degree, I took courses on molecular and cell biology, biochemistry, genetics and physics. I was introduced to the topic of social responsibility in science by the molecular biologist and physicist Maurice Wilkins, then head of the newly created biophysics department at King's College London. The topic of gender in science has since taken an exciting form, opening up new directions for research, while improving its quality and efficacy.

In November, the third Gender Summit will take place in Washington DC under the leadership of the US National Science Foundation (www.gender-summit.com). The summit will feature discussions about understanding and addressing sex and gender issues in basic and applied science.

The three-day programme includes a wide range of topics delivered by more than 100 speakers. Attendees will be able to learn about the effects that sex differences have at the fundamental level of biochemical processes involved in cell regulation; about dimorphic effects in the regenerative properties of stem cells; and about how insights into the differences between the metabolic profiles of women and men can transform diagnosis, therapy and health economics. This is timely: when I attended the 38th Federation of European Biochemical Societies Congress in St Petersburg, Russia, a few weeks ago, I was surprised to see no mention of sex and gender differences in the titles of programmed talks.

The most important thing that scientists can do is to acknowledge that there are differences between male and female cells, and design experiments with this in mind. Do not combine male and female cells separate them out, ideally performing the same experiment in each group. If working with only one sex or gender, then specify that, and explain why. Animal and human studies should abide by the same rules.

Peer reviewers, editors and funders can help to bring about this change by insisting that researchers determine whether and how sex and gender could influence their findings. After its 2007 analysis, Pain released guidelines that state medication trials must include sufficient numbers of men and women. In March 2012, the American Physiological Society issued a policy requiring identification of sex or gender in papers on animal or human studies (see go.nature.com/bmvgiz). Every member of the scientific community has the power and responsibility to do the same for cells.

Elizabeth Pollitzer is director of Portia in London. Portia is a non-profit organization that addresses gender issues in science. e-mail:elizabeth@portiaweb.org.uk

1. Deasy, B. M. et al. J. Cell Biol. 177, 73-86 (2007).

2. Penaloza, C. et al. FASEB J. 23, 1869-1879 (2009).

3. Mittelstrass, K. et al. PLoS Genet. 7, e1002215 (2011).

4. Wizemann, T. M. \& Pardue, M.-L. (eds) Exploring the Biological Contributions to Human Health: Does Sex Matter? (National Academy Press, 2001).

5. Jagsi, R. et al. Cancer 115, 3293-3301 (2009).

6. Greenspan, J. D. et al. Pain 132, S26-S45 (2007).

7. Du, L. et al. J. Biol. Chem. 279, 38563-38570 (2004). 